\title{
Development of Impulse Heavy Current Grounding Test System
}

\author{
Xianghan Wang, Min Dai, Qinghua Peng \\ China Electric Power Research Institute, 430074 Wuhan City, P.R.China. \\ wxhmac@126.com
}

Keywords: impulse heavy current, lightning wave, grounding test, circular returning electrode, split type impulse current generator

\begin{abstract}
A impulse heavy current grounding test system is designed to research impulse characteristics of grounding devices.Structure and test ability of the system are introduced. The system is composed of four impulse current generators symmetrically installed around a return electrode with $20 \mathrm{~m}$ radius. Each generator is designed by low-conductance type and it's maximum charging voltage is $1000 \mathrm{kV}$. The generators are charging and discharging synchronously. The loop inductance is reduced in this system and the current output capability is enhanced. The system can simulate lightning current diffusion under the ground, and generate multiple impulse waveforms on high peak current. When load resistance equals $4 \Omega$, an $8 / 20 \mu$ s lightning impulse current of peak value $100 \mathrm{kA}$ is generated. When load resistance equals $28.49 \Omega$, a $15 \mathrm{kA} 2.6 / 50 \mu \mathrm{s}$ lightning impulse current is provided.The test system is helpful for further research of grounding devices' impulse characteristic and the electrode spark effect.
\end{abstract}

\section{Introduction}

The response of impulse current flowing through grounding devices and it's surrounding soil is a fast and complex process. Simulation, prototype test and model test are frequently used to research the process. Simulation has the advantage of high efficiency and low cost. Prototype test and model test can relatively reveal the response process, though both methods still have some deficiencies. First, the test peak current is usual less than the actual value of lightning peak current. Second, the test current diffusion is different from lightning current. The low test current limits a further research on the impulse characteristics of grounding devices. The inaccurate current diffusion causes difference between test and actual situation, for example the transient ground potential rise characteristics. In order to solve these problems, Electric Power Research Institute of SGCC designed an impulse current grounding test system which can generate a heave current and simulate the lightning current diffusion accurately.

The system is composed of 4 impulse current generators symmetrically installed on a return electrode. The electrode's radius is $20 \mathrm{~m}$ and buried $1 \mathrm{~m}$ underground horizontally. The test current through the grounding devices to the electrode spread evenly like the lightning current. The system capacitance is $1.44 \mu \mathrm{F}$, rated charging voltage is 1000 kilovolts. Different peak current waveforms can be generated under different loop loads, such as a $100 \mathrm{kA} 8 / 20 \mu$ s impulse current under $4 \Omega$ and a $15 \mathrm{kA} 2.6 / 50 \mu$ s impulse current under $28.49 \Omega$.

\section{Structure of the System}

The system has 4 outdoor closed-structure generators, evenly located on a circle with radius of 20m. Generators charge and discharge simultaneously. At the discharge moment, 4 currents flow through 4 separate aluminum pipes from each generator's top to the center of the circle, the total current flows through a current divider into grounding devices then spreads in the soil to a 20m-radius return electrode which connecting the generators. Fig.1 shows the impulse current grounding test system. 


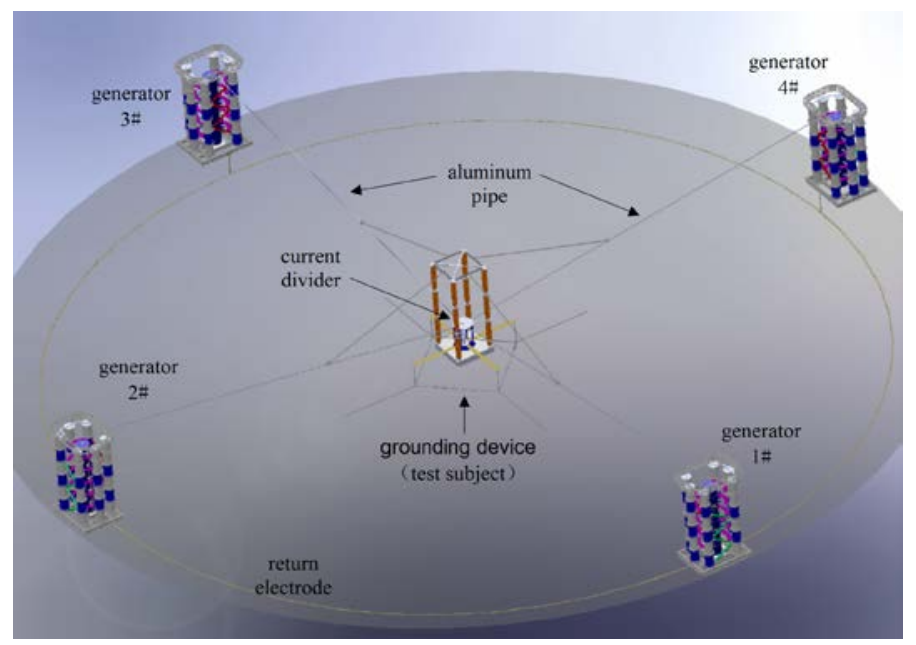

Fig. 1 The impulse current grounding test system

The synchronous discharge generates heavy impulse current and the underground current spreads evenly, which simulates a relative actual lightning stroke. For example each part creates 25kA and the total current will be $100 \mathrm{kA}$.

Generators.

The impulse current grounding test system has a huge loop impedance. Using single generator needs higher rated charge voltage to create heavy current, which causes insulation problem and higher cost.

To reduce the impedance, a gigantic generator are designed separately to 4 parts. Each one are paralleled to charge and discharge synchronously. The advantage is to reduce the inductance, to increase the power output, and to limit the discharge damage to every sphere gap.

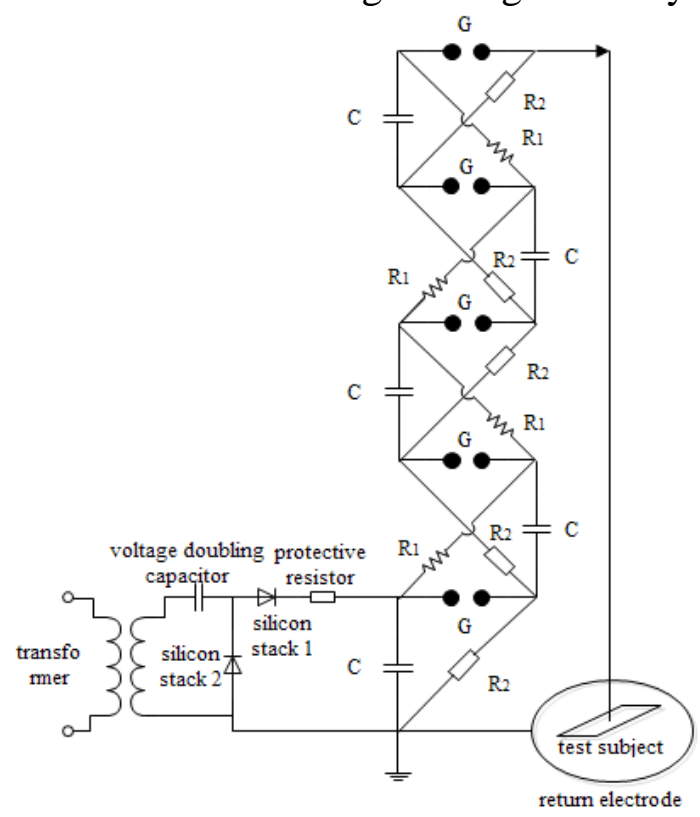

Fig. 2 Circuit of single impulse current generator

Fig.2 shows the circuit of single impulse current generator. $\mathrm{C}$ is capacitor, $\mathrm{G}$ is discharge sphere gap, R1 is charging resistor, R2 is wave tail resistor. The generator has 5 level capacitor, each level has $1.8 \mu \mathrm{F},(30.6 \mu \mathrm{F}-200 \mathrm{kV}$ impulse capacitor paralleled). The out shell has some functions like good insulation, dust-proof and water-proof. A turbine roof ventilator is installed for air convection and heat dissipation.

The discharge sphere gap is sealed in closed insulation cylinder, each gap has a observe window on the cylinder. Air filter and blower are installed at the bottom to provide clean air for keeping gap from circumstance change.

The generator charging with constant voltage controlled by silicon, each level's voltage is modified continuously till reach the maximum rated $200 \mathrm{kV}$. Safe-grounding device is installed, 
when the emergency stop button is pushed the capacitor is grounded by protective resistor.

Each generator has a low inductance design as showed in Fig.3. When the discharging occurs, 5 capacitors and 5 gaps connect in series, current flows from top of generator to grounding device buried in the center of the circle then spread to return electrode which connect the capacitors. The current flow through the gap in opposite directions to reduce the inductance. This structure reduce the generator's discharging inductance, height and cost.

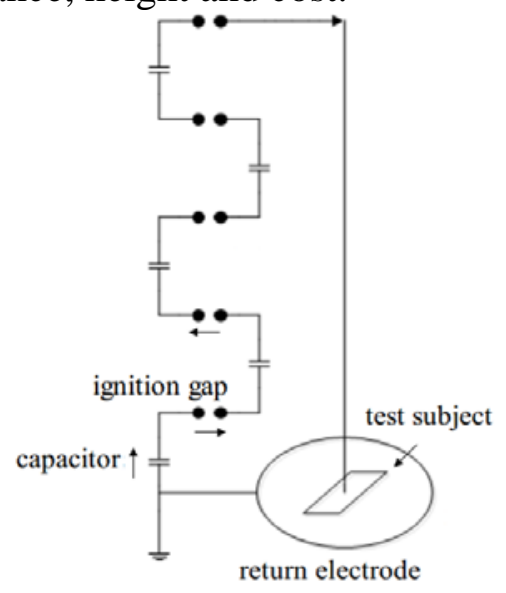

\section{Synchronous discharge.}

Fig. 3 Generator discharging circuit

The generators' discharge including 2 respects, the multilevel discharge inside the generator and the discharge between the generators.

The discharge inside generator depends on the voltage-distance curves. Each gap is adjusted to the critical distance for the corresponding voltage. When the ignition gap (the bottom gap) triggered by a high voltage $(10 \mathrm{kV})$, the rest capacitors and gaps discharge in proper order from bottom to top. This multilevel discharge has a high success rate, so the discharge between the generators becomes an important factor.

The test system used a multiple-trigger system, which sends 4 ignition signal through 4 separate optical fibers to generators. The maximum distance between generators is almost $120 \mathrm{~m}$. Considering the velocity of light is about 300000 kilometres per second, the $0.4 \mu$ s time difference can't be overlooked for a standard $8 / 20 \mu$ s waveform.

Thus different trigger times for each generators are set based on different distance and each generator's discharge characteristic to ensure the synchronous discharge between generators and the superposition of currents.

The trigger time adjustment based on No. one generator(1\#), using multiple channel oscilloscope to compare the rest generators peak current time with 1\# generator's, each time difference is inputted to the trigger. After several adjustments the total current wave becomes smooth waveform which means the discharge is synchronous.

\section{Measurement system.}

A 100kA coaxial tube-type current divider is used for the current measurement. The divider's resistance value is $0.0020684 \Omega$, response time less than $80 \mathrm{~ns}$, maximum output voltage $300 \mathrm{mV}$.

A weakly damped-capacitive-voltage-divider for measuring voltage has a shielding ring on the top, which designed for $1200 \mathrm{kV}$ lightning voltage waveform.

To avoid high potential damage, the measurement system use Uninterrupted Power Supply(UPS) and optic electronic isolation device. Oscilloscope and photovoltaic conversion module use UPS services, and these devices are enclosed in a full metal shielding cabinet to prevent electromagnetic pulse influence.

\section{The Test System Parameters}

The test system has a large scale test loop. The maximum test subject diagonal-size reaches $15 \mathrm{~m}$, together with return electrode and aluminum pipes, add up to a huge inductance which become a major difficulty of heavy current output. 
The system requests to output $8 / 20 \mu$ s and $4 / 10 \mu$ s underdamping waveforms at different load resistance. According to that the inductance $\mathrm{L}$, capacitance $\mathrm{C}$ and charging voltage $\mathrm{U}$ are calculated under different circumstance.The parameters are listed in Table 1.

Table 1 Electrical parameters of impulse current circuit(waveform $8 / 20 \mu \mathrm{s}$ and $4 / 10 \mu \mathrm{s}$ )

\begin{tabular}{ccccc}
\hline Front time/time to half value $(\mu \mathrm{s})$ & $\mathrm{R}(\Omega)$ & $\mathrm{C}(\mu \mathrm{F})$ & $\mathrm{L}(\mu \mathrm{H})$ & $\mathrm{U}(\mathrm{kV})$ \\
\hline $8 / 20$ & 3 & 2.14 & 35.25 & 723.94 \\
$8 / 20$ & 4 & 1.61 & 47.00 & 965.25 \\
$8 / 20$ & 5 & 1.29 & 58.75 & 1206.56 \\
$4 / 10$ & 3 & 1.07 & 17.63 & 723.94 \\
$4 / 10$ & 4 & 0.80 & 23.50 & 965.25 \\
$4 / 10$ & 5 & 0.64 & 29.38 & 1206.56 \\
\hline
\end{tabular}

A $2.6 / 50 \mu$ s overdamping waveform is also requested. This waveform needs higher impedance because the steep front time, which will restrain the peak current. Table 2 shows different parameters for overdamping waveform.

Table 2 Electrical parameters of impulse current circuit(waveform 2.6/50 $\mu \mathrm{s}$ )

\begin{tabular}{ccccc}
\hline $\begin{array}{c}\text { Front time/time } \\
\text { to half value } \\
(\mu \mathrm{s})\end{array}$ & $\mathrm{U}(\mathrm{kV})$ & $\mathrm{I}(\mathrm{kA})$ & $\mathrm{L}(\mu \mathrm{H})$ & $\mathrm{R}(\Omega)$ \\
\hline $2.6 / 50$ & 350 & 10 & 41.43 & 33.24 \\
$2.6 / 50$ & 450 & 15 & 30.44 & 28.49 \\
$2.6 / 50$ & 550 & 20 & 25.58 & 26.12 \\
\hline
\end{tabular}

The test system has 4 generators, each generator has 5 levels, each level has $1.8 \mu \mathrm{F}$ capacitance. The system available capacitance range covers from $0.3 \mu \mathrm{F} \sim 7.2 \mu \mathrm{F}$ and can be adjusted for different test scenes, like $8 / 20 \mu \mathrm{s} 、 4 / 10 \mu$ s and $2.6 / 50 \mu$ s with different impedance.

The system parameters are finally determined on the basis of different waveforms, different test subjects and equipment economy, especially considering the underground impedance is hard to predict. Two modes are defined, one is a $100 \mathrm{kA}, 8 / 20 \mu$ s wave generated when $\mathrm{U}=965 \mathrm{kV}$, $\mathrm{C}=1.44 \mu \mathrm{F}, \mathrm{L}=47 \mu \mathrm{H}$, and $\mathrm{R}=4 \Omega$. The second mode is a $15 \mathrm{kA}, 2.6 / 50 \mu$ s wave when $\mathrm{U}=450 \mathrm{kV}$, $\mathrm{C}=2.4 \mu \mathrm{F}, \mathrm{R}=28.49 \Omega$ and $\mathrm{L}=30.44 \mu \mathrm{H}$.

Based on the modes simulations of different electrical parameters are taken with ATP draw,a graphical and mouse-driven preprocessor to the ATP version of the Electromagnetic Transients Program (EMTP). Fig.4 and 5 for mode 1, Fig.6 and 7 for mode 2.

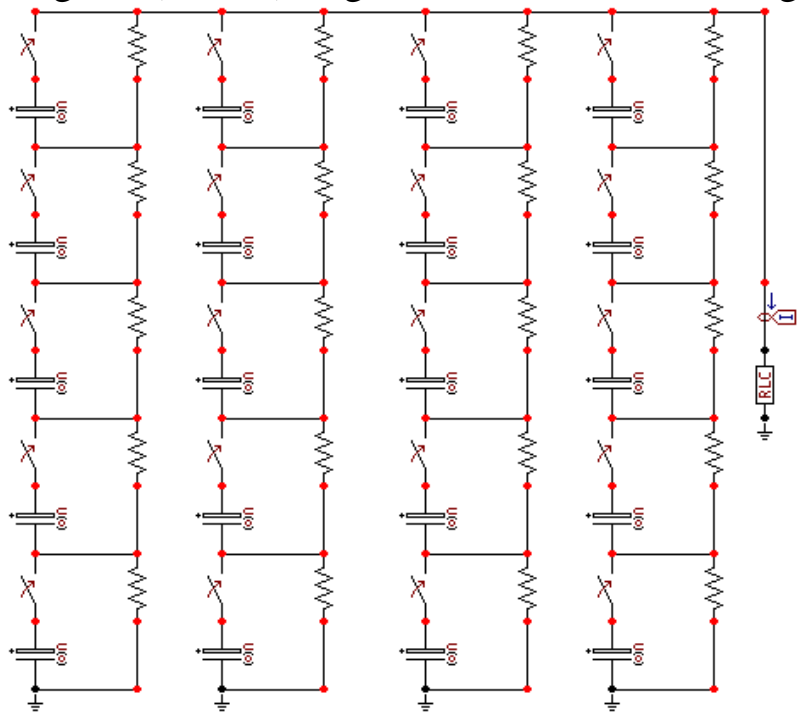

Fig. 4 Test system simulation(waveform $8 / 20 \mu$ s)

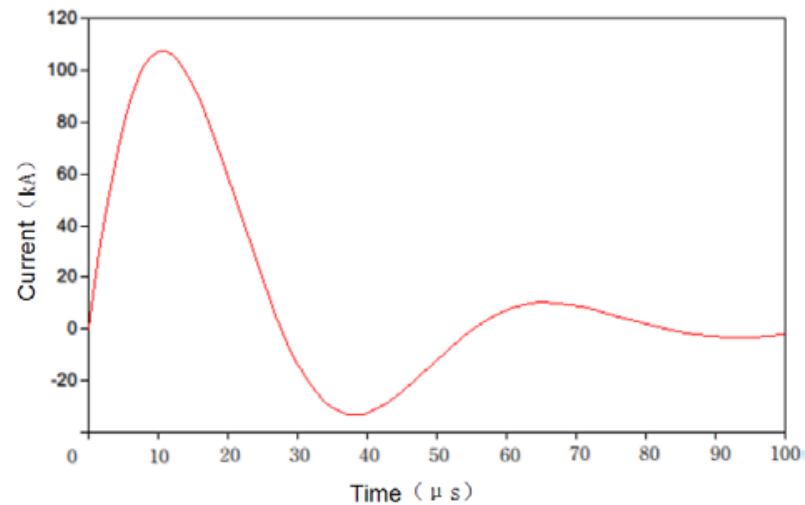

Fig. 5 Impulse current wave simulation (waveform $8 / 20 \mu$ s) 


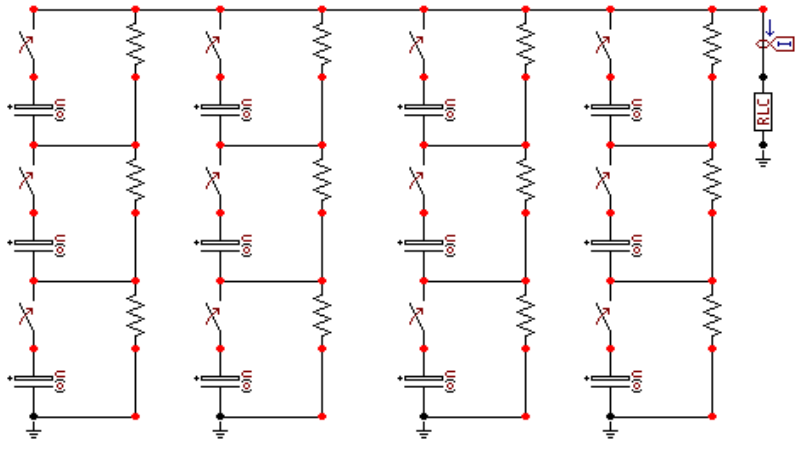

Fig. 6 Test system simulation(waveform $8 / 20 \mu \mathrm{s}$ )

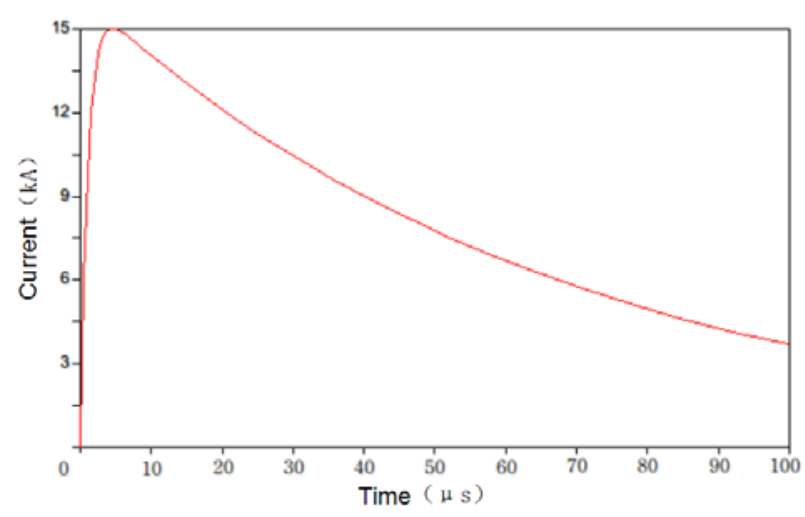

Fig. 7 Impulse current wave simulation(waveform $2.6 / 50 \mu \mathrm{s}$ )

The simulation current waveforms are similar to lightning's from Fig.5 and Fig.7, and the impedance will be adjusted during the field test.

\section{The Impedance Adjustment}

The system's U, C and I are determined in advance, remaining the $\mathrm{R}$ and $\mathrm{L}$ to be the last unknown key parameters because the underground $\mathrm{R}$ and $\mathrm{L}$ must be measured in field test.

The impedance of a single generator discharge loop is made up of two parts which will be measured differently. One is the overground impedance (Rs and Ls), including the generator body and the aluminum pipes. The other underground impedance ( $\mathrm{Rx}$ and $\mathrm{Lx}$ ) includes grounding device, soil and return electrode. A copper bar, which has the impedance $\left(\mathrm{R}_{\mathrm{cu}}\right.$ and $\left.\mathrm{L}_{\mathrm{cu}}\right)$ measured by a $\mathrm{LCR}$ meter, is needed in the measurement. Fig. 8 shows the measurement circuit .

First measurement is to build overground and copper bar circuit as Fig.8 a). Based on the known $\mathrm{R}_{\mathrm{cu}}$ and $\mathrm{L}_{\mathrm{cu}}$, the Rs and Ls will come out because the whole loop impedance can be calculated from an impulse test wave. The result is $\mathrm{Rs}=0.98 \Omega$ and $\mathrm{Ls}=20.78 \mu \mathrm{H}$.

The copper bar is removed and 4 generators are paralleled in the second measurement according to the Fig. 8 b). By calculation from a test wave, the loop resistance is $2.01 \Omega$ and loop inductance is $11.06 \mu \mathrm{H}$. So the underground $\mathrm{Rx}$ and Lx are known as $1.765 \Omega$ and $5.865 \mu \mathrm{H}$.

Four paralleled generator's impedance equals a quarter of a single generator, which increases the choice of underground impedance, also increases the choice of grounding devices because the less of Rs and Ls, the more of Rx and Lx. Especially in this large scale test loop, it's very hard to reduce the soil impedance.

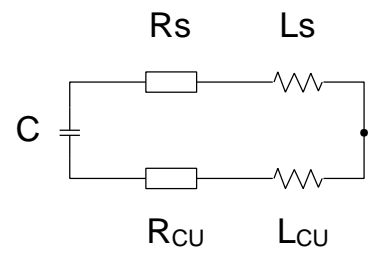

a)loop impedance of overground and copper bar

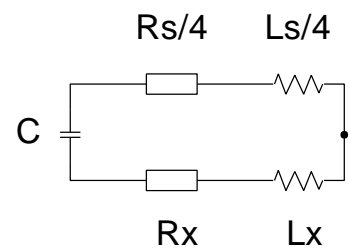

b)loop impedance of overground and underground

Fig. 8 Measurement circuit of loop inductance and loop resistance

\section{The Test System Discharge Test}

Impulse current tests of $8 / 20 \mu \mathrm{s}$ and $2.6 / 50 \mu \mathrm{s}$ are carried out to verify the output current performance.

$100 \mathrm{kA}, 8 / 20 \mu \mathrm{s}$ impulse current test.

A $100 \mathrm{kA}, 8 / 20 \mu$ s positive impulse current waveform is generated when the charging voltage reaches $925 \mathrm{kV}$, after $2.4 \Omega$ adjustable resistance and $34 \mu \mathrm{H}$ adjustable inductance are added to the test loop. Fig.9 shows the record of current. Based on the wave data the loop impedance is calculated as $4.333 \Omega$ and $48.074 \mu \mathrm{H}$. After the Rs/4 and Ls/4 are subtracted from the loop impedance, 
the impulse load resistance is $4.088 \Omega$ and inductance is $42.879 \mu \mathrm{H}$, which fulfills the request of a $100 \mathrm{kA}, 8 / 20 \mu$ s waveform at $4 \Omega$ load resistance.

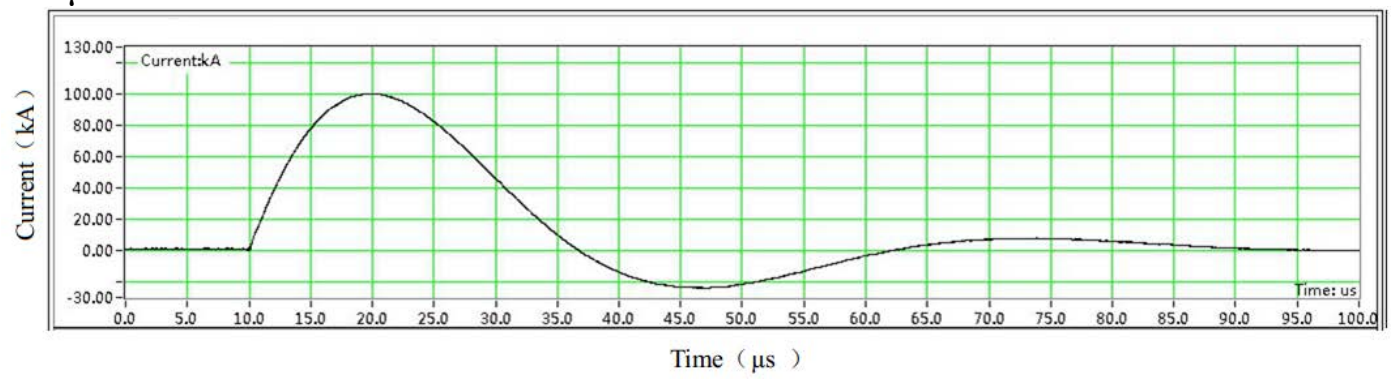

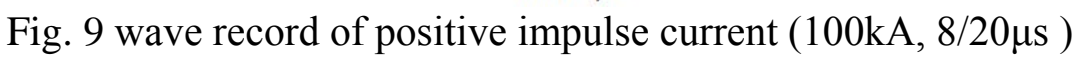

$15 \mathrm{kA}, 2.6 / 50 \mu \mathrm{ss}$ impulse current test.

Adjustable resistance and inductance are also added to the test loop according to the above. When the charging voltage equals $438 \mathrm{kV}$, loop resistance equals $28.49 \Omega$, loop inductance equals $30.44 \mu \mathrm{H}$, a $15 \mathrm{kA}, 2.6 / 50 \mu \mathrm{s}$ impulse current is generated. Fig. 10 shows the record of current.

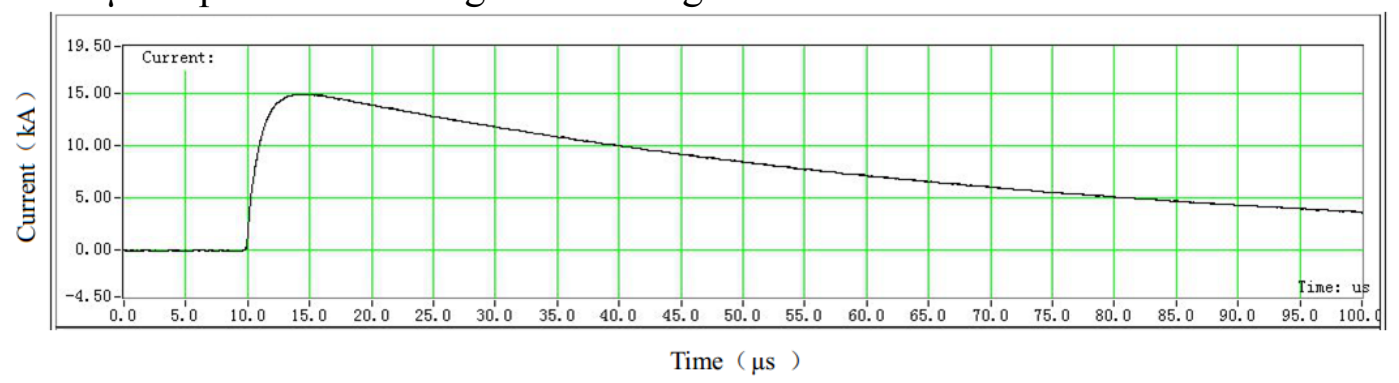

Fig. 10 wave record of positive impulse current $(15 \mathrm{kA}, 2.6 / 50 \mu \mathrm{s})$

\section{Conclusion}

Four impulse current generators are parallel installed on a return electrode of radius $20 \mathrm{~m}$ in equal distance. The loop impedance is reduced to increase more choice of the test subjects. This system can provide multiple heavy impulse currents under different circumstance and accurately simulate lightning current diffusion underground.

In field test, a $100 \mathrm{kA}, 8 / 20 \mu$ s positive impulse current waveform is generated with the load resistance equals $4.088 \Omega$ and load inductance equals $42.879 \mu \mathrm{H}$. A $15 \mathrm{kA}, 2.6 / 50 \mu \mathrm{s}$ impulse current is generated with the loop resistance equals $28.49 \Omega$ and loop inductance equals $30.44 \mu \mathrm{H}$. The test system's abilities provide a powerful equipment for further research of grounding devices' impulse characteristic and the electrode spark effect.

\section{References}

[1] Jinlian HE, Rong ZENG. Power System Grounding Technology. Beijing,China: Science Press, 2007.

[2] Guangrun XIE. Power System Grounding Technology. Beijing,China: Water Resource and Electric Power press, 1991.

[3] Zecun ZHOU. High Voltage Technology. Beijing,China: China Electric Power Press, 2007.

[4] Xianlu CHEN, Yugen LIU, Yong HUANG. Grounding. Chongqing,China: Chongqing University Press, 2001.

[5] Geri A. Non-linear behavior of ground electrodes under lightning surge currents: computer modeling and experimental results. IEEE Transactions on Magnetics, 1992, 28(2),1442-1445.

[6] Sekioka S, Sonoda T, Ametani A. Experimental study of current-dependent grounding resistance of rod electrode. IEEE Transactions on Power Delivery, 2005, 20(2),1569-1576.

[7] Yanqing GAO, Research on mechanism of soil breakdown and transient characteristics of 
grounding systems. Beijing,China: Tsinghua University, 2003.

[8] Habjanic A, Trlep M. The simulation of the soil ionization phenomenon around the grounding system by the finite element method. IEEE Transactions on Magnetics, 2006, 42(4),867-870.

[9] Jinlian HE, Xianlu CHEN. The simulation theory of impulse characteristics of transmission line tower grounding device. Journal of Tsinghua University(Natural Science Edition), 1994, 34(4),38-43.

[10]Jinlian HE, Rong ZENG, Shuiming CHEN,et al. Simulating experiments of the impulse resistance characteristics of transmission-line grounding devices. Journal of Tsinghua University(Natural Science Edition), 1999, 39(5),5-8.

[11]Changzheng XIA, Cixuan CHEN. Impulse experiment for real extended grounding electrode in unit length. High Voltage Engineering, 2001, 27(3),34-35.

[12]Xuemin HAN, Changzheng XIA, Jianhui YU, et al. Simulation experiment on potential distribution for grounding electrode of transmission tower under impulse current. High Voltage Engineering, 2011, 37(10),2464-2470.

[13]Bo ZHANG, Shaofeng YU, Weizheng KONG, et al. Experimental analysis on impulse characteristics of groun ding devices under high lightning current. High Voltage Engineering, 2011, 37(3),548-554.

[14]Rengyu ZHANG, Changyu CHEN, Changchang WANG. High-voltage Testing Technology. Beijing,China: Tsinghua University Press, 2009.

[15]Xidong LIANG, Changyu CHEN, Yuanxiang ZHOU. High voltage Engineering. Beijing,China: Tsinghua University Press, 2004.

[16]Jingling CHEN, Xueling YAO, Wei SUN. Impulse current technology. Xi'an,China: Xi'an Jiao Tong university Press, 2008. 